\title{
Validity of the Control Preferences Scale in patients with emotional disorders
}

\author{
This article was published in the following Dove Press journal: \\ Patient Preference and Adherence \\ 15 November 2016 \\ Number of times this article has been viewed
}

\author{
Carlos De las Cuevas' \\ Wenceslao Peñate ${ }^{2}$ \\ 'Department of Internal Medicine, \\ Dermatology and Psychiatry, \\ ${ }^{2}$ Department of Personality, \\ Assessment and Psychological \\ Treatments, University of La \\ Laguna, San Cristóbal de La \\ Laguna, Canary Islands, Spain
}

Correspondence: Carlos De las Cuevas Departamento de Medicina Interna, Dermatología y Psiquiatría, Facultad de Ciencias de la Salud - Sección Medicina, Universidad de La Laguna, Campus de Ofra s/n, 3807I San Cristóbal de La Laguna, Spain

Tel +34922 $60952 \quad 1405$

$\mathrm{Fax}+34922$ 31 9353

Email cdelascuevas@gmail.com
Background: The Control Preferences Scale (CPS) is the most frequently used measure of patients' preferred roles in treatment decisions. The aim of this study was to provide data about the validity of CPS in psychiatric care of patients with emotional disorders.

Methods: The original CPS was translated to Spanish using the process of cross-cultural adaptation of self-reported measures as the methodological model for Spanish translation. The final version was tested in a convenience sample of 621 consecutive psychiatric outpatients (461 depressive and 160 anxiety disorders) that also completed the Shared Decision-Making Questionnaire, the Multidimensional Health Locus of Control Scale, the Drug Attitude Inventory, and a questionnaire including sociodemographic and clinical variables.

Results: CPS showed a moderate internal consistency and a good convergent validity. Patients with collaborative and passive preferences expressed a greater reliance on psychotropics. Patients preferring a collaborative role self-reported greater perception of involvement in decision-making about their treatment. Patients preferring a passive role showed a greater external health locus of control. The most common preferred role was the collaborative-passive. Older patients and those under longer treatments preferred a passive role, while patients with higher levels of education preferred a collaborative role.

Conclusion: The CPS is a valid measure of the amount of control that psychiatric outpatients with emotional disorders want to assume in the process of making decisions about their treatment.

Keywords: Control Preferences Scale, psychiatric outpatients, emotional disorders, psychometric properties

\section{Introduction}

Interest in the psychiatric patients' potential role in their mental health care has developed along the last two decades. At present time, there is growing consensus that patients ought to be more involved in their own care. This agreement stems from political ideas, ethical thinking, and research in health care. ${ }^{1}$ Since psychiatric practice is characterized by clinical situations in which more than one reasonable possibility of therapeutic intervention is available with no evidence that any of the options is better than another, it has been suggested that it should be the patients' preferences that guide final selection of treatment. ${ }^{2}$ Moreover, psychiatric patient participation in decision-making meets the ethical principle of patient autonomy and the legal requirement of informed consent and has also been associated to better patients' outcome measures. ${ }^{3,4}$

Depression and anxiety disorders are among the most common illnesses in the community of western countries with estimated lifetime prevalence rates of up to $29 \%$ for anxiety disorders and 19\% for depressive disorders. ${ }^{5}$ Many patients with depression often have significant symptoms of anxiety disorders, ${ }^{6}$ and those with anxiety 
disorders commonly have also depression. ${ }^{7}$ Furthermore, both psychiatric disorders may occur together, meeting criteria for both. ${ }^{8}$ Although until relatively recently, the disorder-specific approach has dominated the way in which depressive and anxiety disorders have been conceptualized and researched, nowadays theory and evidence relating to biological and psychological vulnerabilities, comorbidity, latent structure, cognitive and behavioral maintaining factors, and treatment outcome suggest that commonalities across anxiety and depressive disorders are greater than differences. ${ }^{9-11}$ At present time, patient participation in decision-making represents a key factor to address for improving treatment adherence and clinical outcome of emotional disorders since without treatment, they can last longer and recur more often. ${ }^{12}$

At present time, the accurate measurement of the degree of decisional control that a patient actually wants still represents a big challenge to face. Patient participation in health care decision-making can be placed in an independencydependency continuum that could be expressed as passive to active participation. ${ }^{13}$ The Control Preferences Scale (CPS) is a widely used instrument in decision research to assess patient preferences for involvement in decisions about their health. The control preferences construct is defined as "the degree of control an individual wants to assume when decisions are being made about medical treatment." 14

The aim of this study was to provide data about the validity of CPS in psychiatric care setting according to its feasibility to discriminate among preferences of involvement in health care decisions of patients with depressive and anxiety disorders.

\section{Method}

\section{Participants}

From October 2012 to April 2014, 461 patients with depressive disorder and 120 anxiety disorder consecutive psychiatric outpatients seen in two community mental health centers on Tenerife Island (Canary Islands, Spain) were invited to participate in the study. Each participant received a full explanation of the study, after which each signed an informed consent document. Each participant then filled out a brief sociodemographic survey and the rest of the questionnaires.

The study was carried out in accordance with the code of ethics of the Declaration of Helsinki, and all procedures and consent forms were reviewed and approved by the Ethics Committee of the University Hospital Nuestra Señora de la Candelaria in Santa Cruz de Tenerife.

\section{Measures}

\section{Sociodemographic characteristics and clinical} variables

Age, gender, educational level (primary studies, secondary studies, and university degree), diagnosis (International Classification of Diseases, Tenth Revision F3 and F4 categories), time under psychiatric treatment, number of different drugs used, and the number of different treating psychiatrists were registered.

\section{Instruments}

The amount of control that patients want to assume in the process of making decisions about the treatment of their diseases was measured using the CPS developed by Degner et al. ${ }^{14}$ Card-sorting version of the scale was used in our study. It consists of five "cards" on a board, each illustrating a different role in decision-making by means of a cartoon and short descriptive statement. The examiner asks the respondent to choose the preferred card, which is then covered up and cannot be chosen again; the examiner then asks the respondent to choose the preferred card from the remaining four cards. The procedure continues (four choices) until one card is left. If the second preference is incongruent with the first (nonadjacent pairing, such as card A with card C), the test is explained again, and immediately readministered. In the event of a further incongruence, the test is not readministered, and a preference is not assigned. Administration requires about $5 \mathrm{~min}$. Six scores are possible based on the subject's two most preferred roles: active-active, active-collaborative, collaborative-active, collaborative-passive, passive-collaborative, and passive-passive. These scores are grouped as: active (active-active or active-collaborative), collaborative (collaborative-active or collaborative-passive), or passive (passive-collaborative or passive-passive).

We used the guidelines described in Beaton et $\mathrm{al}^{15}$ for the process of cross-cultural adaptation of self-reported measures as the methodological model for Spanish translation of CPS. In this model, the research team followed five distinct steps. In the first step, translation, two independent bilingual translators, competent in both English and Spanish, translated the original questionnaire from English into Spanish. In the second step, translators reached consensus on the translation of words phrases and items based on the synthesis of the translations, working from the original questionnaire as well as the first translator's and the second translator's versions. The third step was cultural appropriateness and content validity testing, which was performed by five independent 
primary care physicians, psychiatrists, and psychologists. They rated degree that each item of the instrument covers the content that it is supposed to measure as an index for representativeness and content validity. They also rated understandability and translation equivalence (semantic and content equivalence) between English and Spanish version. In the fourth step, the revised Spanish version was backtranslated by another two bilingual translators who were blind to the original English version. This step assured that the meaning of Spanish version was reflected in the backtranslation version. The final step was equivalence testing. In this step, the two English-speaking psychiatrists working in Canada were asked to review and compare the original version in English and the back-translated version in English of the CPS. Following this step the back-translation was compared with original questionnaire by the study directors from Spain and after some minor revisions, the Spanish version was ready to use.

The validated Spanish version of the nine-item Shared Decision-Making Questionnaire (SDM-Q-9) was used to assess the extent to which patients feel they were involved in the process of decision-making in consultation by means of scoring nine items on a six-point Likert scale, ranging from 0 (completely disagree) to 5 (completely agree). ${ }^{16,17}$ Summing up all items leads to a raw total score between 0 and 45, where 0 indicates the lowest possible level of SDM and 45 indicates the highest extent of SDM. Patients completed SDM-Q-9 immediately after their clinical consultation with their psychiatrist and not in the presence of the treating health professional. The Spanish version of the scale showed a high level of internal consistency (Cronbach's alpha $=0.89) .{ }^{17}$

The validated Spanish version of the Form $\mathrm{C}$ of the Multidimensional Health Locus of Control scale (MHLC-C) was used to assess patients' perception about who or what controls their outcomes. ${ }^{18,19}$ The MHLC-C is an 18-item general purpose, condition-specific locus of control selfreport scale that can easily be adapted for use with any medical or health-related condition to assess individuals' beliefs on what influences their health. It is composed of four subscales: an internal locus of control subscale - internality and three external locus of control scales - chance, doctors, and other (powerful) people - that measure control variables with regard to participants' health. Each item includes a belief statement about the patient's medical condition with which she/he may agree or disagree through a six-point Likert scale ranging from strongly disagree (1) to strongly agree (6). For this study, two health locus of control dimensions were assessed, ie, internal and external health locus of control. The six-item internal health control dimension assesses the degree to which patients believe their health is influenced by their behavior, whereas the twelve-item external health control dimension measures the belief that fate/luck (chance original subscale), health care professionals (doctors original subscale), or other significative people (other people original subscale) control patients' health status. The Spanish version of the scale showed moderate levels of internal consistency (Cronbach's alpha: internal $=0.67$; chance $=0.62$; doctors $=0.58$; other people $=0.41) .{ }^{19}$

Patients' subjective responses and attitudes toward their treatment were assessed using the validated Spanish version of the Drug Attitude Inventory-10, ${ }^{20,21}$ a ten-item self-report scale developed to assess patient's belief about the efficacy of drugs. Items represent subjective experience presented as self-report statements with which the patient agrees or disagrees. These are based on actual recorded and transcribed accounts of patients, and response options are true/false only. Each response is scored as +1 if correct or -1 if incorrect. The final score is the grand total of the positive and negative points and ranges in value from -10 to 10 , with higher scores indicating a more positive attitude toward medication. A positive total score means a positive subjective response; a negative total score means a negative subjective response. The Spanish version of the scale provided a moderate level of internal consistency. ${ }^{21}$

\section{Data analysis}

Initial descriptive analyses were performed. To contrast these groups with discrete data, chi-squared analysis was performed. For continuous variables, analysis of variance (ANOVA) analyzes were executed (with Bonferroni tests, when statistical differences were found).

\section{Results}

The 621 patients who agreed to participate in the study had a mean age of $52.4 \pm 13.7$ years (range $18-87$ ), and $75 \%$ were female. Concerning educational level, $10.1 \%$ of patients could only read and write, $34.1 \%$ had completed primary studies, $34 \%$ had completed secondary studies, and $21.7 \%$ had a university degree. The primary diagnoses of respondents were depressive disorders in $74.2 \%$ (461 patients) and anxiety disorders in $25.8 \%$ (160 patients). The average duration of treatment was $86 \pm 97$ months (range 2-600). The mean number of psychotropic drugs used was $2.7 \pm 1.3$ (range $0-7$ ). 
Depressive patients were older $(54.3 \pm 11.1$ vs $48.9 \pm 13$ years, $P=0.000)$, more frequently women $(78.7 \%$ vs $75.2 \%, P=0.001)$, used more psychiatric drugs $(2.8 \pm 1.3$ vs $2.4 \pm 1.3, P=0.000)$, and had a longer history of treatment $(93 \pm 97$ vs $65 \pm 94$ months, $P=0.001$ ) than those with anxiety disorders. Educational level was similar in both diagnoses.

Most patients (441 patients, 66.7\%) preferred a collaborative relationship with their psychiatrists, while 177 (28.5\%) preferred a passive approach and only 30 (16.1\%) an active decisional control. The most common preferred role was the collaborative-passive $(64.9 \%)$ where doctor and patient share responsibility for deciding which treatment is best, with the doctor making the final decision after considering the patient's opinion. The second preferred alternative was passive-passive that registered a $24.2 \%$, followed by passive-collaborative and active-collaborative with $4.3 \%$.

To analyze CPS reliability, the four card choices done by patients were transformed in four items. A Cronbach's alpha of 0.72 was attained pointing out a moderate internal consistency level.

A group of analysis was carried out to contrast if preference groups differed in sociodemographical variables. There were found differences between decision-making preferences and gender of patients $\left[X^{2}(2)=8.31 ; P=0.016\right]$. This data indicate how collaborative preference was the clearest option for both male (65.6\%) and female (63.1\%). Active role was the less preferred option also for both genders (male, 9.5\%; female 5.6\%). Taking into account the four collaborative options (active-collaborative, collaborative-active, collaborative-passive, and passive-collaborative), there were no differences among them $\left[X^{2}(3)=4.26\right]$. There was no difference for diagnosis (anxiety or depressive disorders) and preference group: $X^{2}(2)=1.45$. Also, there were no differences among collaborative preferences $\left[X^{2}(3)=3.35\right]$.

According level of education, chi-squared analysis showed a statistical significance $\left[X^{2}(6)=29.01 ; P=0.000\right]$. Though there is a general tendency for a collaborative option, these data also support a tendency for collaborative experience as education level increases (can read and write, $47.1 \%$; primary studies, 58.7\%; secondary, 68.2\%; university, $73.7 \%$ ), and a tendency for passive experience as educational level decreases (read and write, 47.1\%; primary, 33.2\%; secondary, 24.8\%; university, 20.4\%). No differences were found for collaborative preferences $\left[X^{2}(9)=7.88\right]$ where all levels of education have preferred a collaborative-passive option (read and write, $83.7 \%$; primary, $83.1 \%$; secondary, 84.0\%; university, $83.3 \%$ ).

Table 1 represents ANOVA contrasts for continuous variables. As can be observed, age registered a statistical
Table I ANOVA among three groups of participation preferences in medical decision-making in different sociodemographical, attitudes to drugs, shared decision-making, and locus of control variables

\begin{tabular}{|c|c|c|c|c|c|c|}
\hline Variables & $\begin{array}{l}\text { Preference } \\
\text { group }\end{array}$ & Mean & SD & $F$ & $P$-value & $\eta^{2}$ \\
\hline \multirow[t]{3}{*}{ Age (years) } & Active & 45.51 & 12.45 & 23.31 & 0.000 & 0.047 \\
\hline & Collaborative & 47.96 & 12.88 & & & \\
\hline & Passive & 54.11 & $|4.5|$ & & & \\
\hline \multirow{3}{*}{$\begin{array}{l}\text { Treatment } \\
\text { duration } \\
\text { (months) }\end{array}$} & Active & 113.65 & 109.32 & 4.80 & 0.008 & 0.010 \\
\hline & Collaborative & 105.46 & 106.44 & & & \\
\hline & Passive & 130.69 & 123.39 & & & \\
\hline \multirow{3}{*}{$\begin{array}{l}\text { Number of } \\
\text { different drugs }\end{array}$} & Active & 2.80 & 1.61 & 0.84 & 0.433 & 0.002 \\
\hline & Collaborative & 2.96 & 1.34 & & & \\
\hline & Passive & 3.04 & $1.4 \mid$ & & & \\
\hline \multirow[t]{3}{*}{ DAI } & Active & 1.72 & 4.61 & 7.60 & 0.001 & 0.016 \\
\hline & Collaborative & 3.79 & 4.04 & & & \\
\hline & Passive & 3.43 & 4.11 & & & \\
\hline \multirow[t]{3}{*}{ SDM-Q-9 } & Active & 17.25 & 11.09 & $12.6 \mid$ & 0.000 & 0.026 \\
\hline & Collaborative & 21.68 & 11.13 & & & \\
\hline & Passive & 18.14 & 10.53 & & & \\
\hline \multirow[t]{3}{*}{ MHLC internal } & Active & 24.74 & 8.06 & 0.49 & 0.612 & 0.001 \\
\hline & Collaborative & 24.54 & 7.19 & & & \\
\hline & Passive & 24.05 & 7.41 & & & \\
\hline \multirow[t]{3}{*}{ MHLC external } & Active & 38.54 & 8.55 & 4.62 & 0.010 & 0.010 \\
\hline & Collaborative & 40.92 & 8.96 & & & \\
\hline & Passive & 42.12 & 8.88 & & & \\
\hline \multirow[t]{3}{*}{ MHLC chance } & Active & 14.82 & 5.99 & 2.50 & 0.083 & 0.005 \\
\hline & Collaborative & 14.59 & 6.75 & & & \\
\hline & Passive & 15.70 & 7.07 & & & \\
\hline \multirow[t]{3}{*}{ MHLC doctors } & Active & 13.54 & 4.53 & 10.25 & 0.000 & 0.021 \\
\hline & Collaborative & 15.45 & 3.15 & & & \\
\hline & Passive & $|5.5|$ & 3.32 & & & \\
\hline \multirow[t]{3}{*}{ MHLC others } & Active & 10.18 & 3.32 & 1.14 & 0.320 & 0.002 \\
\hline & Collaborative & 10.88 & 3.72 & & & \\
\hline & Passive & 10.92 & 3.59 & & & \\
\hline
\end{tabular}

Abbreviations: ANOVA, analysis of variance; DAl, drug attitudes inventory; MHLC, Multidimensional Health Locus of Control Questionnaire; $P$, probability; SD, standard deviation; SDM-Q-9, nine-item Shared Decision-Making Questionnaire.

significance. Bonferroni test pointed out that older people preferred a passive role, and there was no difference between actives and collaboratives. No disparities were found among collaborative subgroups. Giving treatment duration, again ANOVA was significant. Bonferroni test indicated passive preference has higher treatment time than collaborative, but no differences with actives (and not differences among collaborative groups). Also, no differences were found for the consumption of different prescribed drugs.

According to convergent validity with other self-reports, a more positive attitude to drugs was found for collaborative and passive preferences. Bonferroni test did not found differences between them. Some differences were found among collaborative subgroups $(F(3,443)=5.36 ; P=0.001$; $\left.\eta^{2}=0.035\right)$. Specifically, collaborative-passive patients have 
a more positive attitude to medication than both activecollaborative and collaborative-active groups.

A new difference was found for shared decision-making experienced in the last psychiatric consultation (SDM-Q-9). Collaborative preference scored higher than both passive and active groups. No differences found between passives and actives, and among collaborative subgroups.

External locus of control also attained a statistical significance. Bonferroni test pointed out that collaborative and passive preferences were more external than active preference. According collaborative subgroups, collaborative-passive patients were more external than collaborative-active patients $\left(F(3,443)=3.92 ; P=0.009 ; \eta^{2}=0.026\right)$.

The confidence in their psychiatrists (ie, "doctors" external subscale) was the unique specific locus of control subscale that attained statistical significance, with a similar pattern to general external locus of control. By collaborative subgroups, now collaborative-passive patients were more external than both active-collaborative and collaborativeactive subgroups $\left(F(3,443)=5.73 ; P=0.001 ; \eta^{2}=037\right)$.

\section{Discussion}

This study provides psychometric credibility and relevant data about the validity of CPS in psychiatric outpatient care of patients with emotional disorders. The scale showed a moderate level of internal consistency and an appreciable level of convergent validity. In addition to get reliable information about the degree of decisional control that psychiatric outpatients actually want, the study also pretended through the self-assessment of their preferences to encourage patient involvement and responsibility, to encourage patients to reflect on their role and contribution to the process of decision-making, and to focus on the development of patient's judgment skills about this, so far, novel approach in mental health care.

Most patients with emotional disorders expressed their preference to participate in decision-making about their treatment in a collaborative way in discussing available treatment options but delegating to their psychiatrists to be the ones who make final decision on their behalf. Collaborative-passive was the preferred role for both men and women. Older patients tend to be more likely to want the doctor to decide preferring a passive role. More educated patients preferred a collaborative role while those less educated preferred a more passive role.

According to SDM-Q-9 total score, patients with emotional disorders self-reported moderate level, tending to be low, of perceived involvement in decision-making in their last psychiatric consultation which is consistent with preferences of participation self-reported where most patients informed of experiencing a collaborative-passive role. Patients who preferred a collaborative role self-reported higher scores in SDM-Q-9 indicative of a higher perception of involvement in the process of decision-making in their recent psychiatric consultation. These results support internal validity of CPS.

Another result that supports the internal validity of CPS is the fact that those patients who preferred passive and collaborative roles also scored higher in external health locus of control. Specifically, collaborative and passive patients in their belief that doctors are the ones who determine the outcomes of a patient's health.

It is important to note that although the current research was limited in various ways, however, this study involves a number of strengths. A first limitation of the research was the fact that we registered patients' perceptions of decision-making styles instead of the ideal of study patient consultations directly. Since a cross-sectional survey was carried out, the study could only demonstrate associations and not causality and is only a snapshot: the situation may provide differing results if another time frame had been chosen. Patients' preferences are dynamic, change over time, and are largely dependent on changes in their circumstances (as type of medication used, psychotherapy, severity of illness, etc.), some of which have not been taken into consideration. Finally, the study rely on self-report questionnaires as the only measure to gather data, and this strategy involves the potential weakness to some kinds of response bias, and inferences about correlational and causal relationships may be inflated by the problem of common method. The strengths of this study comprise the considerable number of psychiatric outpatients with emotional disorders who agreed to participate in the study, the diversity of variables included, and the amount of unique information about the target of assessment provides.

\section{Disclosure}

The authors report no conflicts of interest in this work.

\section{References}

1. Florin J. Patient Participation in Clinical Decision-making in Nursing A Collaborative Study Between Patients and Nurses. Örebro Studies in Caring Sciences No 13. Gothenburg, Sweden: Universitetsbiblioteket; 2007.

2. De las Cuevas C, Peñate W. Preferences for participation in shared decision making of psychiatric outpatients with affective disorders. Open J Psychiatry. 2014;4:16-23.

3. Fraenkel L, McGraw S. Participation in medical decision making: the patients' perspective. Med Decis Making. 2007;27(5):533-538.

4. Joosten EA, DeFuentes-Merillas L, de Weert GH, Sensky T, van der Staak CP, de Jong CA. Systematic review of the effects of shared decision-making on patient satisfaction, treatment adherence, and health status. Psychother Psychosom. 2008;77(4):219-226. 
5. Kessler RC, Berglund P, Demler O, Jin R, Merikangas KR, Walters EE. Lifetime prevalence and age-of-onset distributions of DSM-IV disorders in the National Comorbidity Survey Replication. Arch Gen Psychiatry. 2005;62(6):593-602.

6. Gorman JM. Comorbid depression and anxiety spectrum disorders. Depress Anxiety. 1997;4(4):160-168.

7. Hunt C, Issakidis C, Andrews G. DSM-IV generalized anxiety disorder in the Australian National Survey of Mental Health and well-being. Psychol Med. 2002;32(4):649-659.

8. Pollack MH. Comorbid anxiety and depression. J Clin Psychiatry. 2005;66(8):22-29.

9. Barlow DH, Allen LB, Choate ML. Toward a unified treatment for emotional disorders. Behav Ther. 2004;35(2):205-230.

10. Brown TA, Barlow DH. A proposal for a dimensional classification system based on the shared features of the DSM-IV anxiety and mood disorders: implications for assessment and treatment. Psychol Assess. 2009;21(3):256-271.

11. McEvoy PM, Nathan P, Norton PJ. Efficacy of transdiagnostic treatments: a review of published outcome studies and future research directions. J Cogn Psychother. 2009;23(1):20-33.

12. Loh A, Leonhart R, Wills CE, Simon D, Härter M. The impact of patient participation on adherence and clinical outcome in primary care of depression. Patient Educ Couns. 2007;65(1):69-78.

13. Degner LF, Sloan JA. Decision making during serious illness: what role do patients really want to play? J Clin Epidemiol. 1992;45(9):941-950.

14. Degner LF, Sloan JA, Venkatesh P. The Control Preferences Scale. Can J Nurs Res. 1997;29(3):21-43.
15. Beaton DE, Bombardier C, Guillemin F, Ferraz MB. Guidelines for the process of cross-cultural adaptation of self-report measures. Spine. 2000;25(24):3186-3191.

16. Kriston L, Scholl I, Hölzel L, Simon D, Loh A, Härter M. The 9-item Shared Decision Making Questionnaire (SDM-Q-9). Development and psychometric properties in a primary care sample. Patient Educ Couns. 2010;80(1):94-99.

17. De Las Cuevas C, Perestelo-Perez L, Rivero-Santana A, Cebolla-Martí A, Scholl I, Härter M. Validation of the Spanish version of the 9-item Shared Decision-Making Questionnaire. Health Expect. 2015;18(6): 2143-2153.

18. Wallston KA, Stein MJ, Smith CA. Form C of the MHLC Scales: a condition-specific measure of locus of control. J Pers Assess. 1994; 63(3):534-555.

19. De las Cuevas C, Peñate W, Betancort M, Cabrera C. What do psychiatric patients believe regarding where control over their illness lies? Validation of the multidimensional health locus of Control Scale in psychiatric outpatient care. J Nerv Ment Dis. 2015;203(2):81-86.

20. Hogan TP, Awad AG, Eastwood R. A self-report scale predictive of drug compliance in schizophrenics: reliability and discriminative validity. Psychol Med. 1983;13(1):177-183.

21. Robles-García R, Salazar-Alvarado V, Páez-AgrazF, Ramírez-Barreto F. Assessment of drug attitudes in patients with schizophrenia: psychometric properties of the DAI Spanish version. Actas Esp Psiquiatr. 2004;32(3): $138-142$.
Patient Preference and Adherence

\section{Publish your work in this journal}

Patient Preference and Adherence is an international, peer-reviewed, open access journal that focuses on the growing importance of patient preference and adherence throughout the therapeutic continuum. Patient satisfaction, acceptability, quality of life, compliance, persistence and their role in developing new therapeutic modalities and compounds to optimize

\section{Dovepress}

clinical outcomes for existing disease states are major areas of interest for the journal. This journal has been accepted for indexing on PubMed Central. The manuscript management system is completely online and includes a very quick and fair peer-review system, which is all easy to use. Visit http://www. dovepress.com/testimonials.php to read real quotes from published authors. 